\title{
MATERIALS AND APPLICATIONS FOR THIN FILMS IN HYBRID MICROELECTRONICS
}

\author{
G. ZINSMEISTER \\ Balzers AG, Thin Film Electronics Dept., FL-9496 Balzers, Liechtenstein \\ (Received June 28, 1979)
}

\begin{abstract}
The use of thick films in microelectronics has increased in an impressive way during the last years. In contrast to this, thin films have shown a less spectacular but nevertheless steady evolution which concerned mainly more efficient deposition methods (planar magnetron) as well as higher quality films and thus better components and circuits. The present paper aims at illustrating this by some selected examples.
\end{abstract}

\section{RESISTOR FILMS}

In spite of very great research and development efforts during more than 25 years there are still only 2 film materials which are finding wide application for making precision thin film resistors: $\mathrm{NiCr}$ and $\mathrm{Ta}$ (either $\mathrm{Ta}_{2} \mathrm{~N}$ or $\mathrm{TaO}_{x} \mathrm{~N}_{y}$ ). Very low TCR values are attained with $\mathrm{NiCr}$ whilst very good stability values can be reached using Ta-base films.

The main problem with $\mathrm{NiCr}$ is the reproduceability of the thin film parameters because it is necessary to control carefully the alloy composition as well as any gas pick up during the deposition process. The following results, which have been obtained in the author's department, serve to illustrate the kind of performance which can be achieved with $\mathrm{NiCr}$ films (on glass Corning 7059; sheet resistivity $100 \Omega / \square$ after ageing in air for at least 2 hours at $300{ }^{\circ} \mathrm{C}$; contacts consisting of Ti-Pd-Au).

\subsection{Stability}

$\Delta \mathrm{R} / \mathrm{R}$ values for 1000 hours at $125{ }^{\circ} \mathrm{C}$ without load quoted for NiCr films range anywhere from $0.5 \%$ to $0.05 \%{ }^{1,2}$ This is illustrated in Figure 1 for different $\mathrm{NiCr}$ films together with results of a Vishay ${ }^{3} 10 \mathrm{k} \Omega$ bulk metal film resistor as a reference. Reproduceability is such that films with a stability better than $0.05 \%$ can be made with a yield of better than $50 \%$. It is unknown at present whether significantly better stability values are still possible.

Most precision thin film resistors are used in networks. Tracking properties are therefore of greatest importance. Figure 2 shows the stability

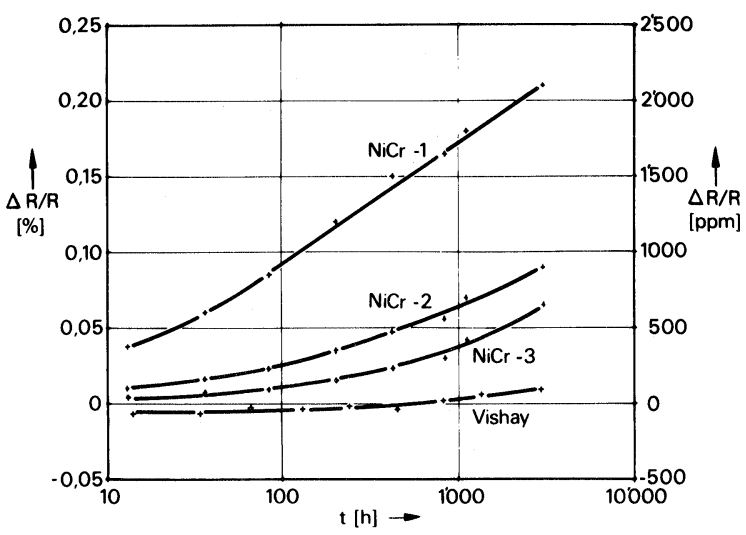

FIGURE 1 Resistance drift of 3 different $\mathrm{NiCr}$ films and a $10 \mathrm{k} \Omega$ Vishay resistor at $125{ }^{\circ} \mathrm{C}$ without load.

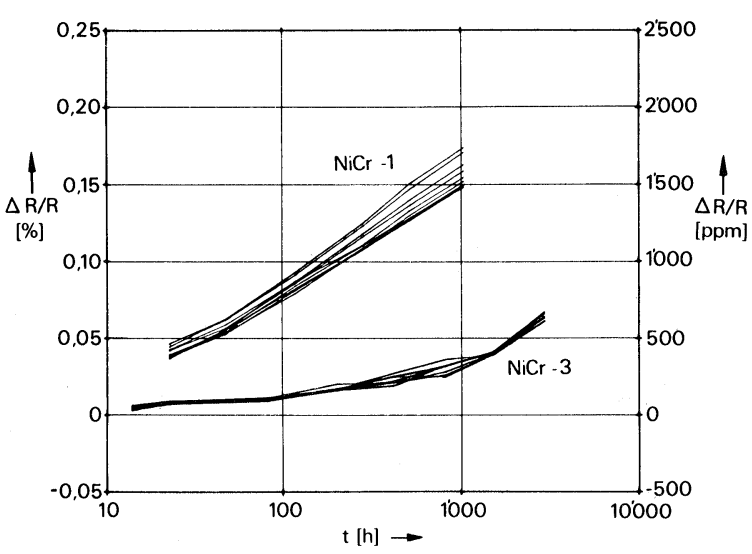

FIGURE 2 Resistance drift of 9 resistors $(2,3 \mathrm{~mm} \times 23 \mathrm{~mm}$, parallel and equally spaced by $5 \mathrm{~mm}$ ) on a 2 in $\times 2$ in substrate. 
values obtained for 9 resistors on a 2 in $\times 2$ in substrate. Experience has shown that the relative drift between the resistors is about $1 / 5$ to $1 / 10$ of the absolute drift. It is therefore imperative to reduce the absolute drift in order to obtain good tracking values, where $\leqslant 0.01 \%$ seems to be the limit which can be obtained at the moment.

\subsection{Temperature Coefficient of Resistance (TCR)}

The TCR of NiCr films can vary between $-50 \mathrm{ppm} /{ }^{\circ} \mathrm{C}$ up to $+150 \mathrm{ppm} /{ }^{\circ} \mathrm{C}$ depending on the deposition conditions. We have found it possible in production to keep the TCR within $\pm 15 \mathrm{ppm} /{ }^{\circ} \mathrm{C}$. This range can be reduced to $\pm 7 \mathrm{ppm} /{ }^{\circ} \mathrm{C}$ by selecting out about $50 \%$ of the plates (see also Figure. 6). These values are measured in the temperature range of $20^{\circ} \mathrm{C}$ to $30^{\circ} \mathrm{C}$. Changing the deposition conditions allows a shift in the TCR in the range $0 \pm 15 \mathrm{ppm} /{ }^{\circ} \mathrm{C}$ without deteriorating the ageing behaviour of the films. Measuring the TCR differentially in the range $-55^{\circ} \mathrm{C}$ to $+125^{\circ} \mathrm{C}$ leads to the curves in Figure. 3. The TCR

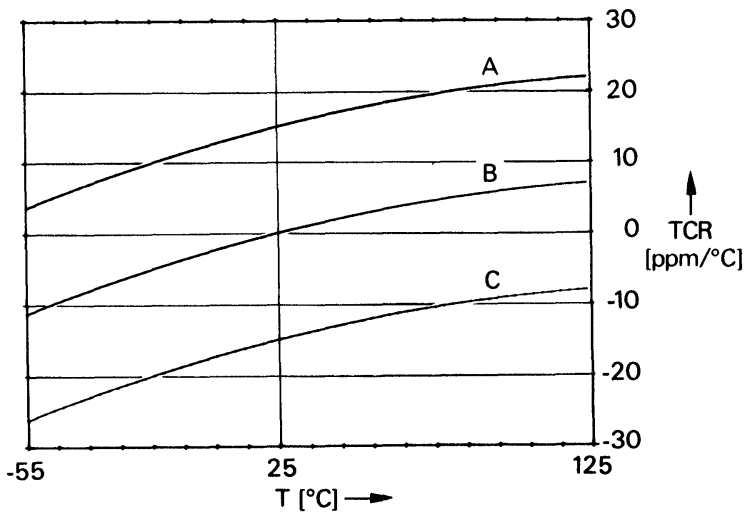

FIGURE 3 TCR as a function of temperature for 3 different $\mathrm{NiCr}$ films $\mathrm{A}, \mathrm{B}$ and $\mathrm{C}$.

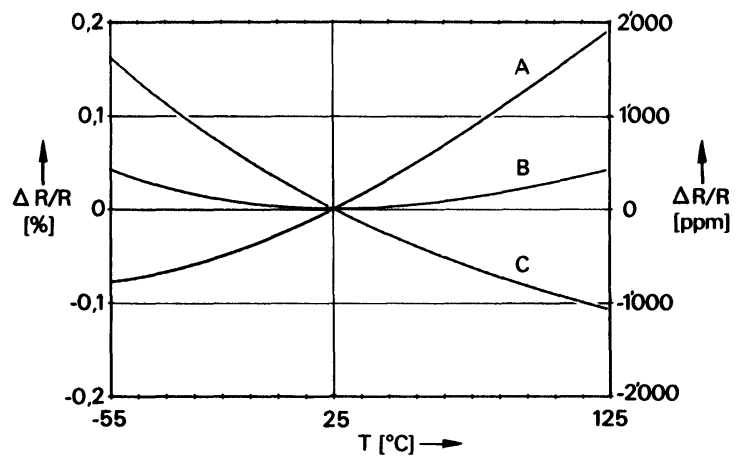

FIGURE 4 Resistance versus temperature curves corresponding to Figure 3.

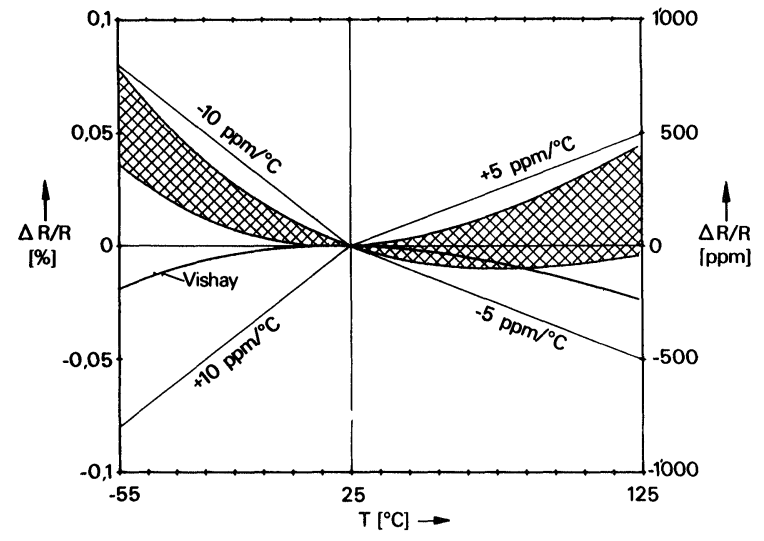

FIGURE 5 Possible resistance temperature specifications if only end values of a temperature interval are specified.

is nonlinear and the curves can only be shifted in parallel but not turned e.g. in a desired more horizontal direction. The temperature dependence of the TCR shown in Figure 3 corresponds to the resistance versus temperature curves given in Figure 4. Usually the resistance values are only specified for the end points of a certain temperature range. If we choose the 2 ranges $-55^{\circ} \mathrm{C}$ to $25^{\circ} \mathrm{C}$ and $25^{\circ} \mathrm{C}$ to $125^{\circ} \mathrm{C}$, then fairly tight tolerances can be kept as shown in Figure. 5. The hatched area in this figure contains the values of 18 resistors measured on 3 different substrates. For a comparison the measured curve for a $10 \mathrm{k} \Omega$ Vishay resistor is also given. This resistor shows an opposite temperature dependence and a very small absolute TCR.

\subsection{Distribution of TCR and $R \square$ Values}

Figures $6 \mathrm{a}, \mathrm{b}$ show the histograms of the values from 58 batches for the TCR and for the $\mathrm{R}_{\square}$ (appr. 7 values measured per batch). Figure $6 \mathrm{c}$ shows the TCR distribution within one batch after the deposition conditions have been changed in order to bring the TCR closer to zero. For the sheet resistivity $R_{\square}$ we find a spread of $\pm 4 \%$ over the average values and taking into account the spread within a batch a total spread $(3 \sigma)$ of $\pm 7 \%$ for all individual resistors can be maintained. It should be possible to improve this value in the future. At the moment tighter tolerances can be obtained if necessary by selection of substrates according to their position during the coating process. 

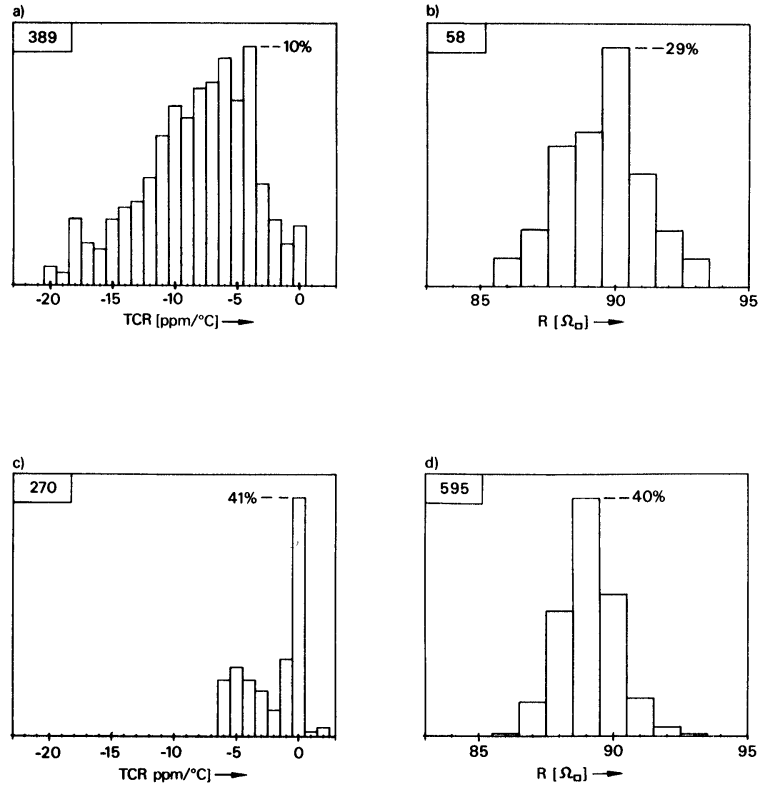

FIGURE 6 Histograms for TCR and $\mathrm{R}_{\square}$ values from 58 batches $(a, b)$ and from one batch $(c, d)$ but latter not contained in $(a, b)$. Number in upper left corner is the total of values used.

\subsection{Aspect Ratio}

In order to cover a wide resistance range it is necessary to etch resistors with very different length to width ratios (aspect ratio). An investigation of the TCR as a function of the aspect ratio using 4 point contacts has not shown any change in the range of 10 to $2.10^{4}$ squares. For aspect ratios $<10$ making contacts with a low interface resistance and the measuring technique itself become the dominant problem.

Long term stability is certainly not influenced by the aspect ratio in the range of 5 to 3000 squares. Larger resistors are being tested at the moment whilst for resistors in the range from 0.01 to 1 square, improved measurement methods have first to be devised. Nevertheless we are convinced from the measurements so far, that ageing is not influenced by the aspect ratio in the range of 0.01 to $2.10^{4}$ squares. This refers to untrimmed resistors which have been strongly preaged in air (at least 2 hours at $300{ }^{\circ} \mathrm{C}$ ). In connection it might be mentioned that so far we have not found a protective coating on silicone basis which improves the long time stability of $\mathrm{NiCr}$ films in air. This is in agreement with other published reports. $^{4}$

\section{RC NETWORKS}

All recent attempts to produce $\mathrm{RC}$ film networks with temperature compensation $(\mathrm{TCR}+\mathrm{TCC} \approx 0$ ) are based on Ta films. In all cases mentioned in this paragraph the capacitors are formed by anodically oxidizing a suitable capacitor grade film and evaporating $\mathrm{NiCr}+\mathrm{Au}$ afterwards on top of the oxide to form the counterelectrode.

The standard materials introduced by Bell Telephone Laboratories ${ }^{5}$ were $\mathrm{Ta}_{2} \mathrm{~N}$ films for resistors $\left(\mathrm{TCR}=-100 \pm 30 \mathrm{ppm} /{ }^{\circ} \mathrm{C}\right)$ and anodized $\beta$-Ta for capacitors $\left(\mathrm{TCC}=+250 \mathrm{ppm} /{ }^{\circ} \mathrm{C}\right)$. In order to achieve temperature compensation, the TCR of the resistor film was made more negative by adding oxygen. ${ }^{6}$ This leads to $\mathrm{TaO}_{x} \mathrm{~N}_{y}$ (appr. $x=0.3$, $y=0.2)$ films with a TCR of $-250 \mathrm{ppm} /{ }^{\circ} \mathrm{C}$. The resulting $\mathrm{RC}$ product has a temperature coefficient of $\pm 50 \mathrm{ppm} /{ }^{\circ} \mathrm{C}$ over the range $-40{ }^{\circ} \mathrm{C}$ to $+65^{\circ} \mathrm{C}$. W. Anders ${ }^{7}$ introduced $\mathrm{TaN}_{x}(x=0.1$ to 0.2$)$ films for making capacitors with an improved temperature stability, a lower dissipation factor and a smaller TCC (appr. $140 \mathrm{ppm} /{ }^{\circ} \mathrm{C}$ ) in comparison to capacitors made from $\beta$-Ta films. The lower TCC allowed furthermore the use of the standard $\mathrm{Ta}_{2} \mathrm{~N}$ resistor films.

In the aforementioned cases the capacitor film is first vacuum deposited, then patterned, anodized and afterwards, in a second vacuum cycle, the resistor film is deposited. The first practicable proposal to make RC networks out of one single film was made by $\mathrm{H}$. Baeger. ${ }^{8,24} \mathrm{He}$ observed that from films of $\mathrm{TaO}_{x} \mathrm{~N}_{y}(x=0.3 ; y=0.1)$ either resistors or capacitors could be made with TC's of $150 \mathrm{ppm} /{ }^{\circ} \mathrm{C}$ compensating each other. A $13 \Omega / \square$ film is deposited which increases to $60 \Omega / \square$ after anodization and annealing and which serves at the same time as a resistor as well as the bottom electrode of the capacitor(s). This rather high sheet resistivity limits the upper useful frequency to about $2 \mathrm{kHz}$.

This limitation is overcome if according to B. Kaiser ${ }^{9}$ A1 or A1 Ta is deposited between the resistor and the capacitor film. After having formed the resistor photoresist image, the A1 film on top of the meander is etched away laterally and any capacitor material on top of it is lifted off. The remaining A1 film under the capacitor gives a good conductivity which enables extension of the frequency limit. Already $0.1 \mu \mathrm{m} \mathrm{A} 1$ increases the frequency limit to $30 \mathrm{kHz}$ for a dissipation factor $<0.3 \%$. This technique gives great freedom in the selection of the resistor and capacitor film, the only restriction being that they should not be attacked by the A1 etchant. 

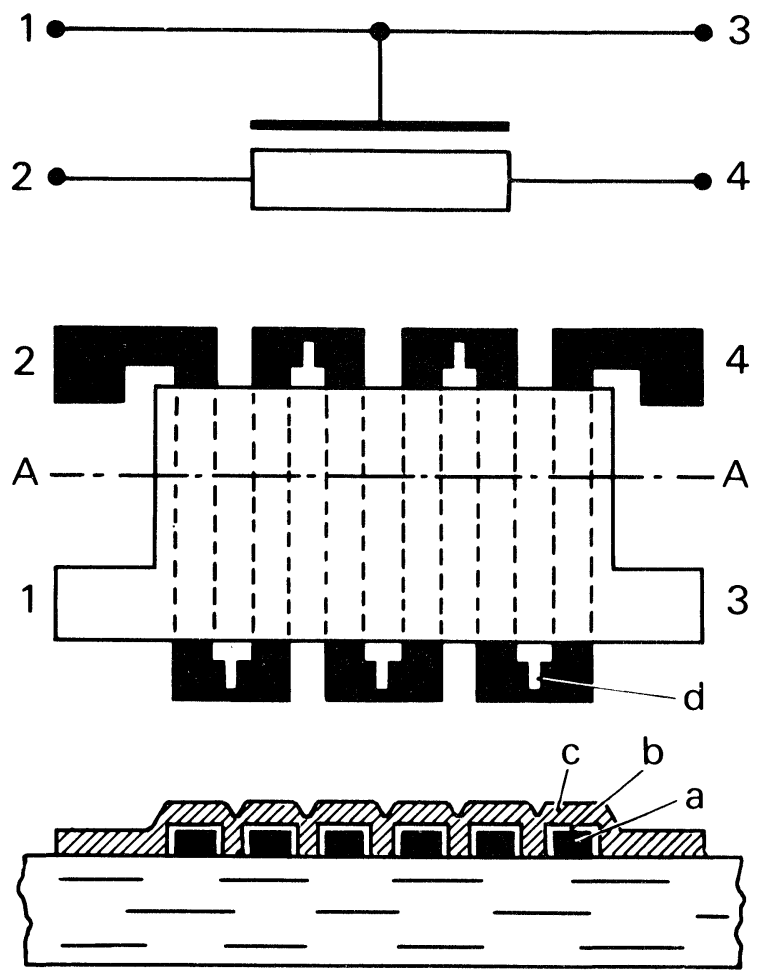

FIGURE 7 Distributed RC element which allows trimming of the resistive bottom electrode: a) resistive electrode, b) dielectric, c) top conductive electrode, d) trim cuts. ${ }^{24}$

The frequency limit of RC networks can be pushed up to $5 \mathrm{MHz}^{10,11}$ if distributed elements are used. In this case one of the capacitor electrodes is made of resistive material. However two problems are associated with this proposal: the design of the circuits becomes rather complex but Renz ${ }^{10}$ gives a class of useful circuits for simplifying the design.

The trimming of distributed networks is usually difficult. This is overcome by the arrangement shown in Figure 7, which allows a fairly precise trimming of the resistive electrode of the capacitor.

None of the three last mentioned circuits is in industrial production but the yield of circuits made on the basis of $\mathrm{TaO}_{x} \mathrm{~N}_{y}$ films has been surprisingly high $(>80 \%)$ under laboratory conditions. ${ }^{14,24}$

\section{CONTACT FILMS}

The enormous price increase for precious metals has led to many new proposals for cheaper contact materials. The most detailed investigations have been made about $\mathrm{Cu} / \mathrm{Fe} / \mathrm{Cu}$ covered by a solder layer ${ }^{15}$

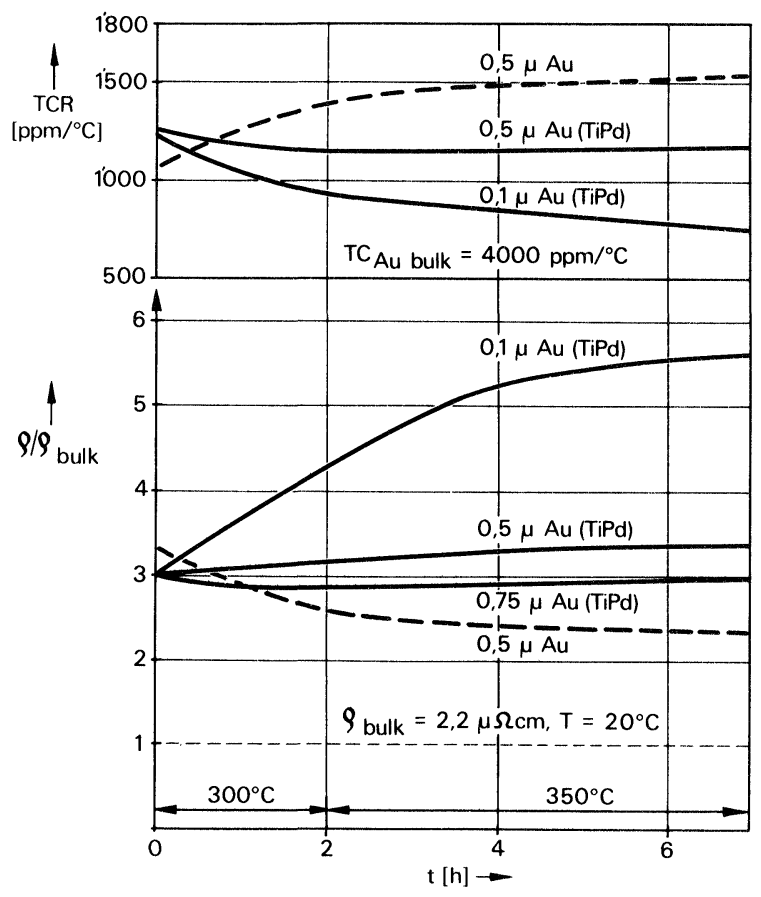

FIGURE 8 Resistivity and TCR of $\mathrm{Au}$ and $\mathrm{Au}$ (TiPd) contacts on glass as a function of annealing conditions.

and $\mathrm{Ti} / \mathrm{Cu} / \mathrm{Ni} / \mathrm{Au} .{ }^{16}$ However both contacts will withstand temperatures only up to $250{ }^{\circ} \mathrm{C}$ in air.

As our NiCr films require an anneal of at least $300{ }^{\circ} \mathrm{C}$ in air we have to stay with a sandwich contact like TiPdAu. The resistivity is very much influenced by the post deposition annealing process (Figure 8). The resistivity of a pure Au film will decrease because the annealing process reduces the number of defects introduced during deposition whilst grain growth helps to further reduce the resistivity ${ }^{17}$ and to increase the TCR. In a sandwich film this conductivity increase is more than compensated by the diffusion of the $\mathrm{Pd}$ barrier material into the $\mathrm{Au}$ film. ${ }^{18}$ This is responsible for the different resistivity changes in function of the Au thickness. Very detailed studies ${ }^{17-20}$ have lead to the following picture: the coefficient of grain boundary diffusion is about 3 to 5 orders of magnitude higher than the coefficient for diffusion through the grains. At the beginning of an anneal the rapid diffusion along the grain boundaries will transport barrier metal to the $\mathrm{Au}$ surface. This can seriously influence the bondability or solderability of the Au film. This is the reason for the upper temperature limit of the low cost contact: ${ }^{16}$ small amounts of $\mathrm{Cu}$ and $\mathrm{Ni}$ diffuse to the surface wher they form $\mathrm{CuO}$ and $\mathrm{NiO}$. 
Grain boundary diffusion will barely influence the resistivity of the Au film because the amount of foreign atoms in the boundaries is much too small (appr. 0.5at $\%^{18}$ ). The observed change in contact resistivity is therefore entirely due to the much slower diffusion through the grains (volume diffusion). This process is still faster in thin films than in bulk metals because it is enhanced by the great number of defects (dislocations) generated within the grains during the condensation process.

$\mathrm{Ni}$ has a very low coefficient of volume diffusion into $\mathrm{Au}$ or $\mathrm{Cu}$. This explains the excellent stability (small resistance increase) of this contact at temperatures up to $200{ }^{\circ} \mathrm{C} .{ }^{20}$ This combination represents therefore a good and economic contact if no high temperature anneal of the resistors is required.

A good high temperature contact should therefore not only consist of metals with a low coefficient of volume diffusion but the metals should also not form detrimental compounds on the Au surface because grain boundary diffusion cannot be made negligible.

\section{THERMAL PRINTERS}

These printers have the advantage of producing no noise except for the paper transport mechanism. The print heads consist of resistor dots which are heated by current pulses to temperatures between $150{ }^{\circ} \mathrm{C}$ and $400{ }^{\circ} \mathrm{C}$. The resistor dots ( 2 to $10 \mathrm{dots} / \mathrm{mm}$ ) are made of diffused silicon, thick or thin films. For thin film printer heads either $\mathrm{Ta}_{2} \mathrm{~N}^{21,22}$ or $\mathrm{NiCr}^{23}$

(see Figure 9) are being used.

The advantage of thin film printer heads are:-

1) high resolution (small dot size) which is especially important for facsimile printing with grey tones,

2) low power consumption (about $1 / 4$ of thick film print heads) which is advantageous for battery operated, portable instruments; furthermore it

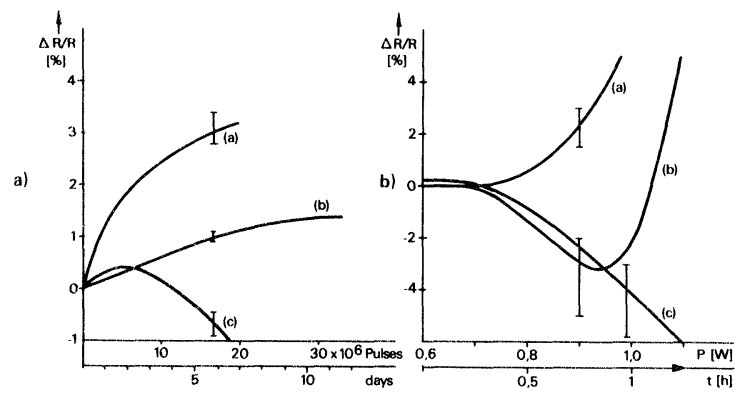

FIGURE 9 Resistance drift of $\mathrm{NiCr}$ films under a) normal printing pulse load and b) accelerated step stress tests. reduces the heat which has to be carried away. The disadvantage at present is the higher price than that of thick film heads.

The main problems with printer heads are:-

1) stability of resistance value under pulse load and

2) durability under mechanical wear and attack by the thermally sensitive compounds on the paper. Relatively thick $(2 \mu \mathrm{m}$ to $10 \mu \mathrm{m})$ insulator films of $\mathrm{SiO}_{2}, \mathrm{Al}_{2} \mathrm{O}_{3}, \mathrm{Ta}_{2} \mathrm{O}_{5}$ or combinations thereof are deposited over the resistor dots as a wear protection in order to achieve life times of $5.10^{6}$ to $5.10^{7}$ pulses.

During the life time the resistance value should not change by more than $5 \%$ to $10 \%$. Figure 9 a shows the resistance drift under a pulse load of $10 \mathrm{~W} / \mathrm{mm}^{2}$ (5 msec power on; $25 \mathrm{msec}$ power off). These results serve also to illustrate again that $\mathrm{NiCr}$ films can show very different ageing behaviour depending on the manufacturing conditions.

In order to shorten the test time, accelerated step stress tests were performed by increasing the pulse power by $0.1 \mathrm{~W}$ each 15 minutes. The results shown in Figure $9 \mathrm{~b}$ reproduce fairly well the qualitative drift behaviour of the resistor dots. Depending on the specification either film (b) or (c) makes it possible to build a high quality print head. The success of the accelerated tests encourages use of this method for predicting the long term drift of $\mathrm{NiCr}$ films in the temperature range of $80{ }^{\circ} \mathrm{C}$ to $175^{\circ} \mathrm{C}$. Our results have shown that such a correlation does not exist. It is therefore still a challenge to find accelerated test methods for precision $\mathrm{NiCr}$ thin film resistors.

\section{ACKNOWLEDGEMENTS}

I would like to thank my collaborators Ing. R. Hoffmann and Dr. H. Diletti for their help during the preparation of this paper.

\section{REFERENCES}

1. See e.g. D. O. Spiller and J. Griessing Proc. Europ. Hybrid Microelec. Conf. (1977); ISHM-Deutschland e.V., München 40

2. L. Groth, Solid State Technol. 20 (1977) No. 3, 45

3. Vishay Intertechnology Inc. 63 Lincoln Highway, Malvern/PA 19355 USA.

4. K. Heid, Proc. El. Comp. Conf. 1977, p. 68.

5. H. Basseches and D. Gerstenberg, Thin Solid Films 12 (1972) 295

6. G. I. Parisi, Proc. El. Comp Conf. 1969 p. 367

7. W. Anders, Thin Solid Films 27 (1975) 135

8. H. Baeger, Thesis, University Stuttgart 1978, see also Refs $12,13,14$

9. B. Kaiser, Thesis, University Stuttgart 1978, see also Refs 12,13 
10. H. W. Renz, Thesis, University Stuttgart 1977, see also Refs $12,13,14$

11. H. W. Renz, European Conf. on Circuit Theory and Design, Lausanne, 1978

12. E. Lüder, Bau hybrider Mikroschaltungen, Springer, Berlin (1977)

13. Int. Conf. on Thin and Thick-Film Technol., Augsburg 1977 NTG-Fachberichte Vol. 60; VDE-Verlag GmbH; 1000 Berlin 12

14. Private communication from Prof. E. Lüder, University of Stuttgart

15. G. Krüger, Thin Solid Films 12 (1972) 335

16. J. M. Morabito, J. H. Thomas and H. G. Lesh, IEEE Trans PHP-11 (1975) 253
17. H. Hieber, F. Betke and K. Pape, Electrocomp. Sci. and Technol. 4 (1977) 89

18. P. M. Hall, J. M. Morabito and J. M. Poate, Thin Solid Films 33 (1976) 107

19. M. A. Nicolet, Thin Solid Films 52 (1978) 175

20. P. M. Hall and J. M. Morabito, Thin Solid Films 53 (1978) 175

21. S. Shibata, K. Murasugi and K. Kaminishi, IEEE Trans PHP-12 (1976) 223

22. Hewlett-Packard Journal Nov. 1976 and April 1978

23. R-Ohm Electronics GmbH, Thermal print head KH 204

24. H. W. Renz et al. Proc. IEEE 67 (1979) 37 

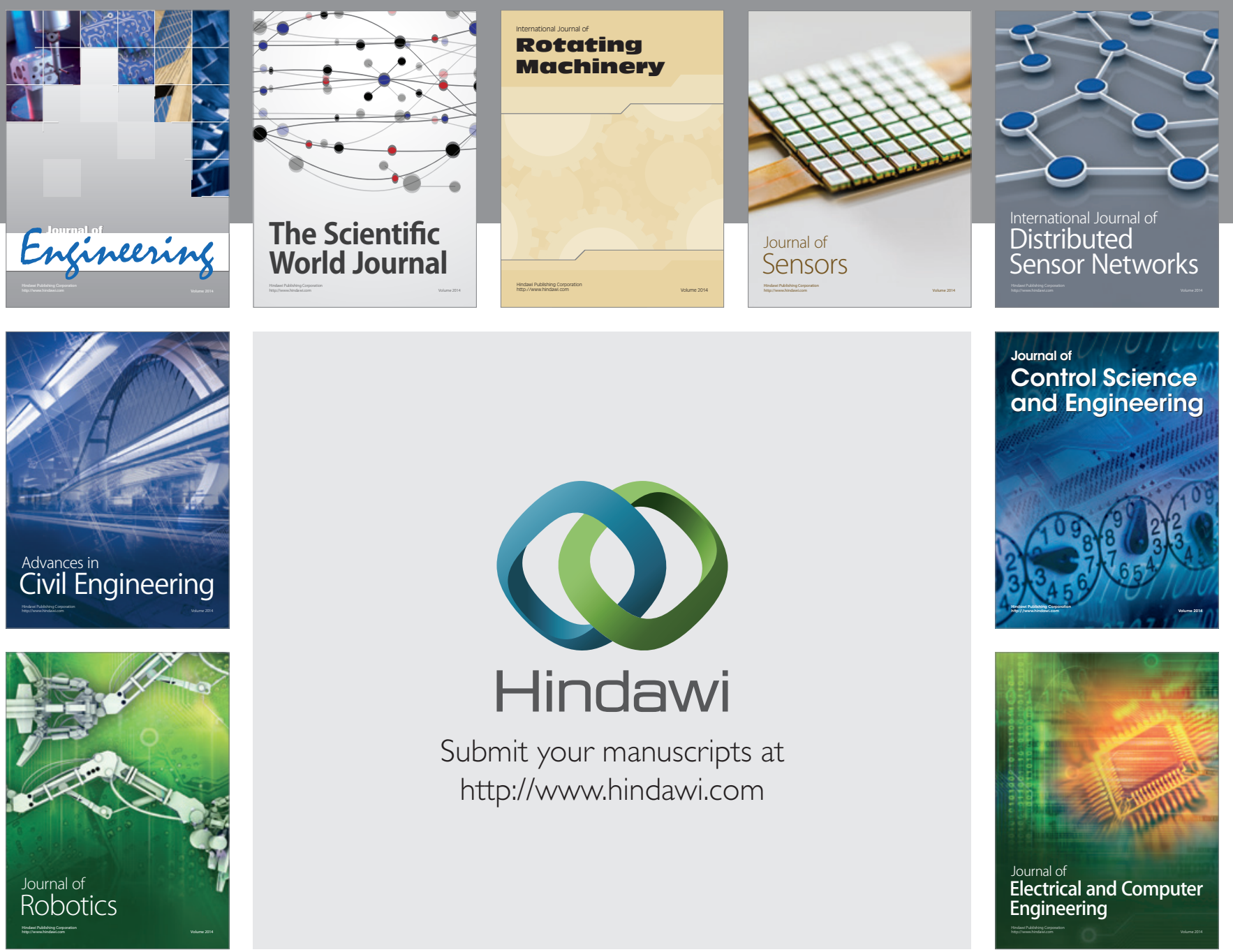

Submit your manuscripts at

http://www.hindawi.com
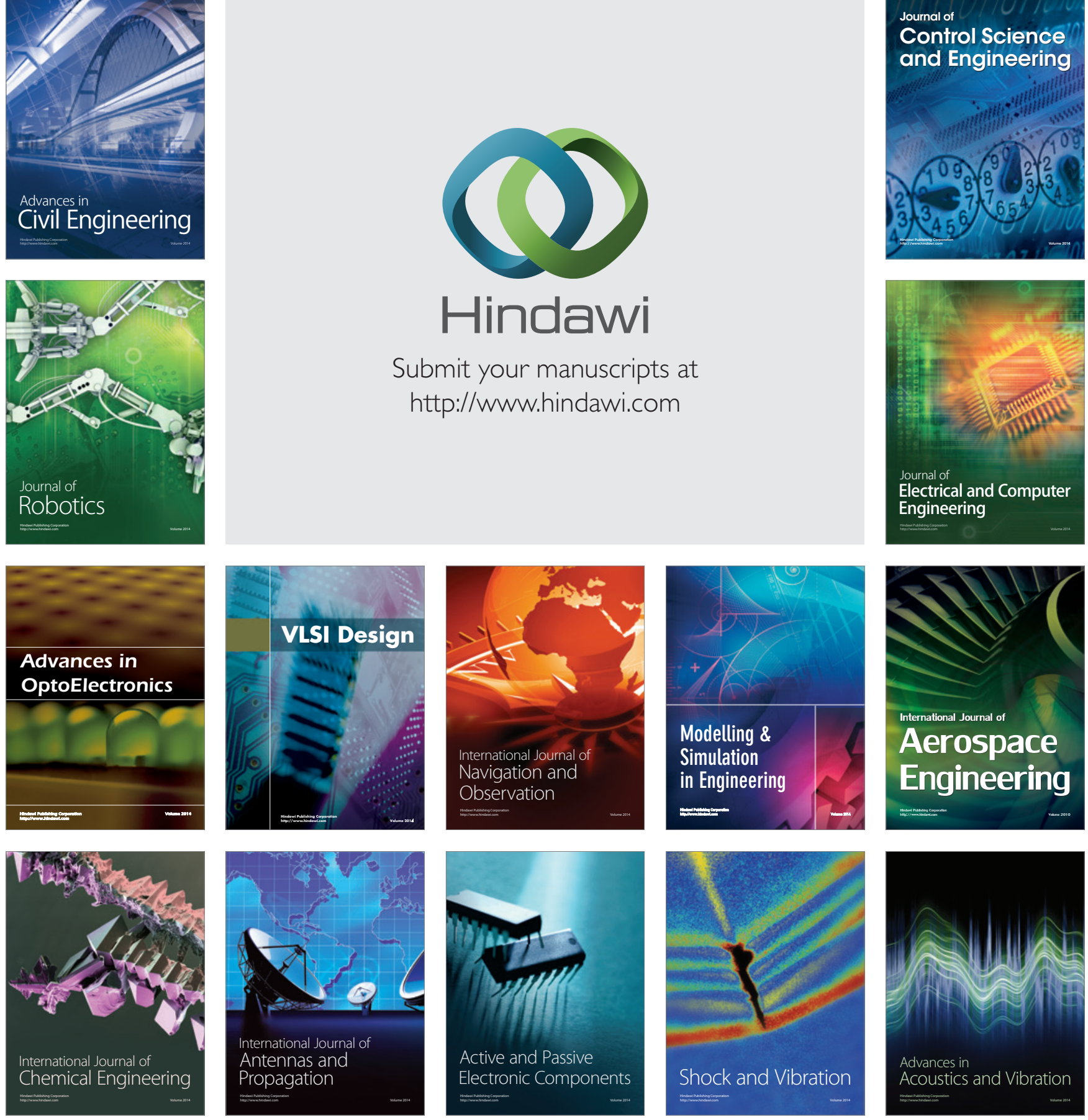